\title{
Jobs for Physicists An EPS Study
}

Following two years of preparatory work the Europhysics Study Conference of the Advisory Committee on Physics and Society looking at the "Employment of Physicists in Europe" took place in Bad Honnef from 26 to 29 October of last year. This was the second EPS Conference on the subject, the first having been held in Erice in 1981 when two medium-term problems were identified: demographic - serious imbalances between the number of physicists trained and the jobs they have traditionally held; structural - inherent difficulties of mobility because of educational inadequacies or compartmental attitudes. The conclusions of the Erice study published in Trends in Physics, the Proceedings of the 5th EPS General Conference, included recommendations on data assembly, age distribution in universities, arousing interest in industry in physics, and interesting physicists in industry.

As a prelude to this recent meeting, the Organizing Committee under its Chairman, Professor John Ziman launched a pilot scheme of data collection from the four countries: France, the Federal Republic of Germany, the Netherlands and the UK. Following this, 21 of the physical societies which are members of EPS and which had indicated interest in the study were invited to prepare reports covering the three main themes: education, recruitment, and employment/unemployment. Eleven reports were received by the time the Conference opened and a further six have since come in.

In the analysis that has been made, the countries have been divided into five main groups: the big western European countries which had formed the pilot study (Group I), the Scandinavian countries (Group II), the smaller "central" western European countries including Ireland (Group III), the "peripheral" countries (Group IV), the smaller eastern European countries (Group V).

Whilst the data are not complete and it is not always easy to be certain that terms are interpreted in the same way in different countries, it would seem that the total number of physicists in Europe (including the USSR) is around 250000 - a figure that is rather less than that quoted at the UNESCO Conference in Istanbul in 1981 (held in association with the 5th EPS General Conference) and in publications of the European Science Foundation. The number of physicists graduating should reach a peak of $9800 / a$ in the year 1990 , and should then drop by about $20 \%$ by the turn of the century. This decline overall is almost entirely a reflexion of the Group I pattern, the others being both numerically smaller and also more stable. In terms of fractions of the total population, the number of physicists in Groups $\mathrm{I}-\mathrm{V}$ is calculated to be respectively, $0.15 \% ; 0.05-0.15 \%$ (Sweden being exceptionally high); 0.05-0.15\% (dominated by the Netherlands and Switzerland); 0.05 except for Israel $0.15 \%$; $0.04-0.15 \%$ (with the GDR at the top end of the scale).

In the more industrialized countries, the break-down into occupations is relatively constant: $15 \%$ school teaching, $15 \%$ university teaching and research, $30 \%$ in industry, $10 \%$ in government service and $30 \%$ in other occupations. Variations that do occur can be explained in terms of the traditional structural differences in research practice from one country to another.

Everywhere the employment situation for physicists seems to be good. There is virtually no unemployment nor prospect of such.

The news is however not all positive and the abridged report of the Secretary (E.W.A. Lingeman) to Council forecast an "impending disaster in school teaching and university teaching all over Europe, mainly because of the lack of good long-term education policies". The first effect will be felt in the secondary schools, to be followed later in the universities as the present peak in the age group (currently around 50) works its way into retirement and the universities find themselves competing in a seller's market. Only the FRG seems to be insulated from the first effect, but simply because of the basic difficulties secondary school teachers find in changing their employment and this could lead to repercussions in due course. In the UK the shortage is already making itself felt.

In at least some of the developing European countries, the message from Erice that there was a shortage of well trained teachers in experimental physics seems to have been taken to heart and the situation is improving. The majority of physicists trained in any case go into
SPIE'S INSTITUTES

FOR ADVANCED

OPTICAL TECHNOLOGIES

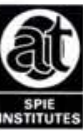

SPIE Volume 634

OPTICAL

AND

HYBRID

COMPUTING

\author{
Second in the Series \\ 38 papers, 485 pages \\ ISBN 0-89252-669-6 \\ Copyright 1987 \\ Editor: H. H. Szu, \\ Naval Research Laboratory \\ 24-27 March 1986 \\ Leesburg, Virginia USA
}

In 1986 a small group of about 40 experts came together in a synergistic manner for four days and three nights in a retreat environment and devoted themselves to assessing and projecting the future of optical computing. This peerreviewed volume is the result of that interaction.

$$
\begin{gathered}
\text { Part One } \\
\text { Algorithms for Linear } \\
\text { and Nonlinear Systems } \\
\text { 13 papers } \\
\text { Part Three } \\
\text { Neural Networks for Computing } \\
8 \text { papers } \\
\text { Part Two } \\
\text { Architectures Based on } \\
\text { Bistable and Molecular Devices } \\
7 \text { papers } \\
\text { Part Four } \\
\text { Application Driven Devices } \\
\text { and System Developments } \\
\text { 10 papers }
\end{gathered}
$$

The concept of the SPIE Institutes for Advanced Optical Technologies developed out of SPIE's desire to foster increased interaction and collaboration among researchers working in emerging optical technologies.

\section{SPIE Member $\$ 65$}

Nonmember North America $\$ 79$ Nonmember All Other Countries $\$ 91$

To order: contact SPIE, Avenue de la Tanche 2, B.1160 Brussels. Belgium; Telephone 2/660.45.11: Telex 25387 AVVAL B. In North America, contact SPIE, P.O. 206/676-3290: Telex 46-7053. 
teaching, but there is still a problem of the best going abroad to better paying jobs. It would seem that there is much that could be done through exchange programmes to encourage a two-way flow. Agreements exist, but their implementation is far from satisfactory and an effort should be made to collaborate with the European Science Foundation to see how an improvement could be brought about.

In the eastern European countries, despite the turn-over of physicists being planned, in practice it is a ceiling that is established and this is never attained. As a result, the shortage is chronic.

Discussions on education at the Conference were inevitably very generalised as systems differ in their detail, but all suffer from huge inertias and from historical attitudes. One desirable change since Erice to be noted however was the reduction to 26 for the average age of gaining a Ph.D. Except in the UK this used to be over 30 .

An improvement in relations between industry and the universities was also recorded, but the academics in many countries bewailed the widening difference in salary levels between the two domains. Whereas industrial salaries have kept pace with inflation, university salaries have not and the gap is now very marked. This must result in major problems for the universities as their budgets get tighter and it is difficult to see how in the future they will be able to hang on to the best people once they have obtained their doctorates. In the short term, the opportunities for the young bright physicist look very promising, but the danger is that we are mortgaging our future.

Further discussions on the conclusions of the Study Conference will take place in Helsinki at the 7th EPS General Conference in August. The full Report totalling 174 pages will be published shortly by the EPS. Participants will receive copies free of charge; further copies may be obtained from the Secretariat at the cost of Sw.Fr. 50.- per copy. For bulk orders (over 10 copies) a discount of $50 \%$ will be given.

Fig. - Estimated number of physics graduates per year based upon birth numbers in the country groups I to $V$ and of Europe, excluding Turkey and the USSR.

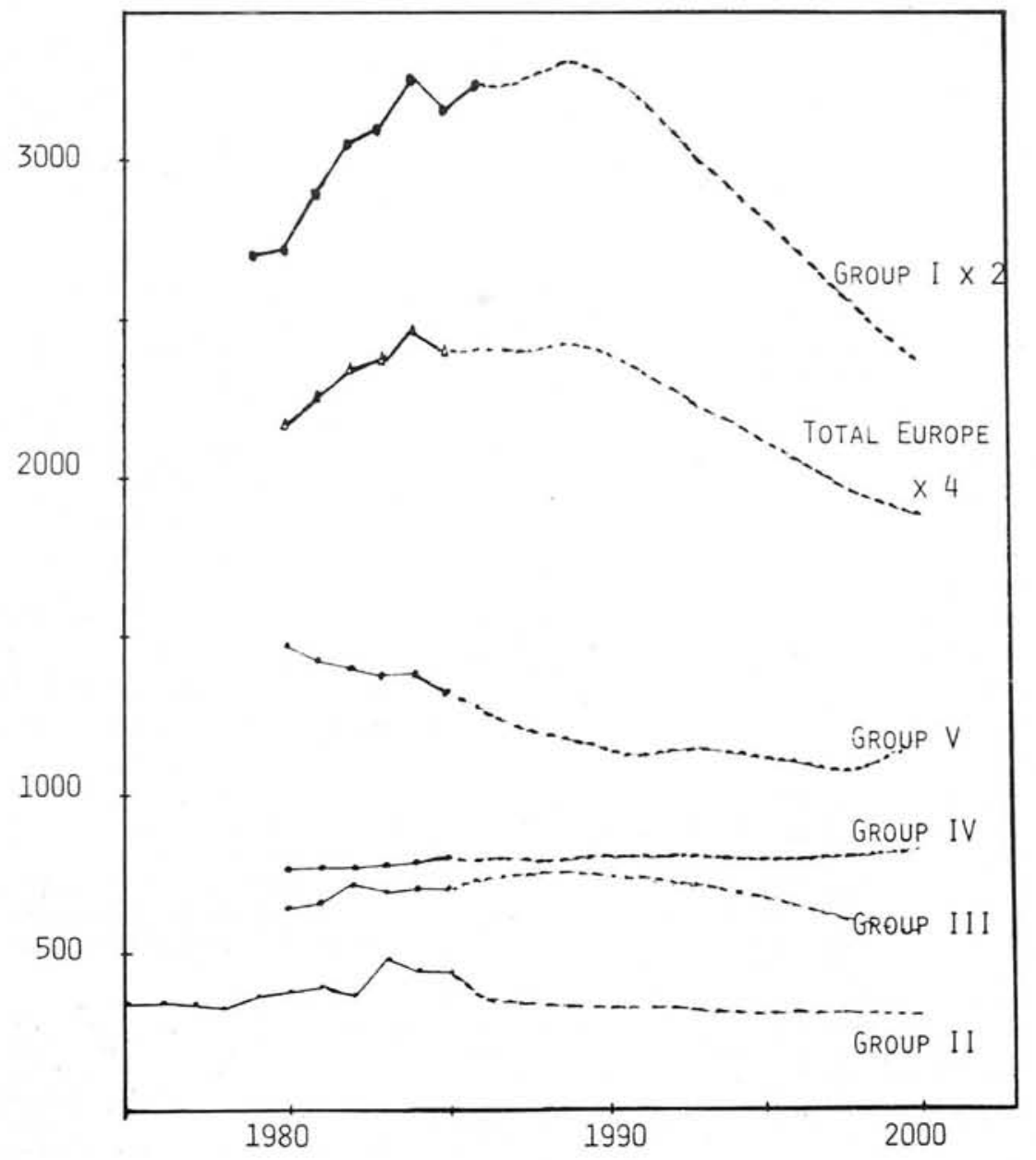

\section{Hewlett-Packard Europhysics Prize 1988}

\section{Call for Nominations}

The Selection Committee for the Hewlett-Packard Europhysics Prize invites nominations for the 1988 award. The prize is given for an outstanding contribution to condensed matter physics within the previous five years, with the potential for leading to advances in the fields of electronic, electrical or materials engineering. Nominations may be submitted by EPS members as individuals or as representatives of a Division or Section.

During this decade the HewlettPackard Prize has been awarded to the following:

$$
\begin{aligned}
& 1980 \text { - O. Krogh Andersen and } \\
& \text { A.R. Miedema } \\
& 1982 \text { - K. von Klitzing } \\
& 1983 \text { - I. Silvera } \\
& 1984 \text { - G. Binnig and H. Rohrer } \\
& 1985 \text { - J. Als-Nielsen and M. Pepper } \\
& 1986 \text { - F. Mezei } \\
& 1987 \text { - I. Yanson } \\
& \text { In order to maintain this extremely }
\end{aligned}
$$
high standard, it is necessary that the Committee receive proposals which represent the breadth and strength of European condensed matter physics. It is also important that the submitted nominations be complete, and it is our experience that this is not always the case. They should comprise at least:

- a detailed motivation for the award, including a clear definition of the work and its significance;

- a brief curriculum vitae of the nominee;

- a list of relevant publications.

It is also extremely helpful if we receive letters of support from authorities in the field, in which the importance of the work is evaluated. These can with advantage also be sollicited from nonEuropean physicists.

EPS members who know of a qualified candidate for the Hewlett-Packard Prize are urged to submit a complete nomination to the Selection Committee, to arrive before the end of August. All information will be treated as strictly confidential.

Nominations should be addressed to: Selection Committee, $\mathrm{H}-\mathrm{P}$ Europhysics Prize EPS

POB 69

$\mathrm{CH}-1213$ Petit-Lancy 2

\section{A.R. Mackintosh}

Chairman,

Hewlett-Packard Prize Selection Committee 